\title{
Prevalence of overweight and obesity and their associations with blood pressure among children and adolescents in Shandong, China
}

\author{
Jing Dong ${ }^{1+}$, Xiao-Lei Guo ${ }^{1+}$, Zi-Long Lu ${ }^{1}$, Xiao-Ning Cai ${ }^{2}$, Hui-Cheng Wang ${ }^{3}$, Ji-Yu Zhang ${ }^{1}$, Liu-Xia Yan²
} and Ai-Qiang $\mathrm{Xu}^{1 *}$

\begin{abstract}
Background: Obesity and high blood pressure (BP) are public health problems all over the world. Some studies have reported a positive association between them in children and adolescents. The purpose of this study was to assess the prevalence of overweight and obesity and their associations with BP among school children and adolescents in Shandong, an important province in eastern China.

Methods: In 2011, we conducted a cross-sectional population-representative survey in Shandong, China. A total of 4898 children and adolescents aged 6-17 years were randomly selected from 140 counties/districts using a multistage random cluster sampling. Weight, height and BP were measured by a trained physician or pediatrician, and information about age, gender and place of residence was obtained using questionnaires. Obesity and high BP were defined according to age- and gender-specific Chinese reference data for children.

Results: A total of 4898 (100\%) children and adolescents provided complete information. The prevalence of overweight, obesity and overweight plus obesity were $10.9 \%, 8.7 \%$ and $19.6 \%$, respectively. Boys were more likely to be overweight or obese than girls $(P<0.05$ for overweight; $P<0.001$ for obesity). The prevalence of overweight plus obesity was highest among children aged 6-11 years (22.3\%). BP and the prevalence of high BP increased with increasing body mass index (BMI). With age and sex adjusted, odds ratios (ORs) for high BP were [OR 2.2;95\% $\mathrm{Cl}$ 1.7-2.8) in overweight and [OR 3.6;95\% Cl 2.6-4.9] in obese children.

Conclusion: The representative survey confirms high prevalence of overweight and obesity among children and adolescents in Shandong. Childhood obesity is a strong risk factor for high BP. Intervention programs should be implemented to combat the growing obesity epidemic.
\end{abstract}

Keywords: Prevalence, Overweight, Obesity, Adolescents, Blood pressure

\section{Background}

Over the last few decades there has been a worldwide increase in childhood obesity [1,2]. In the world, the prevalence of overweight and obesity among children and adolescents increased by $2.5 \%$ from $1990-2010$. At the current rate of increase, the prevalence among the world's children is expected to exceed $9 \%$ by 2020 [3]. Similar findings are being seen in China. In the past

\footnotetext{
* Correspondence: freedom.dj1@163.com

${ }^{\dagger}$ Equal contributors

'Department of Non-communicable Disease Control and Prevention, Shandong Center for Disease Control and Prevention, 16992 Jingshi Road, Jinan 250014, China

Full list of author information is available at the end of the article
}

30 years, China has gone through a rapid economic growth leading to expansion of urban areas and enhancement of living standards [4]. National data points to an increase in the prevalence of childhood obesity in recent years [5].

The etiology of childhood obesity is complex and influenced by genetic and environmental factors [6]. Childhood obesity increases the risk of adulthood obesity and is associated with other chronic diseases. National studies conducted in 2005 and 2010 indicated a positive association between blood pressure (BP) and obesity or body mass index (BMI) among Chinese children and adolescents $[7,8]$. A similar study conducted by Zhang 
in Shandong in 2005 revealed the same findings $[9,10]$. However, in the above mentioned study by Zhang, data was drawn from only three cities to represent the children and adolescents in Shandong, which was an important eastern littoral province with seventeen cities and a population of 96 million.

Therefore the study aimed to estimate the current prevalence of overweight and obesity and their associations with BP in a randomly selected representative sample among children and adolescents aged 6-17 years in Shandong.

\section{Methods}

\section{Subjects}

In 2011, we conducted a cross-sectional populationrepresentative survey in Shandong, China. The target population was children and adolescents, aged 6-17 years, who lived in Shandong with their parents or guardians for at least 6 months. A total of 4898 children and adolescents aged 6-17 years were randomly selected using a multistage random cluster sampling. First, a total of 140 counties/districts (in seventeen cities) in Shandong were stratified by geographic distribution (Eastern, CentralSouthern, and North-Western), and by residence status (urban and rural). Second, using a proportional probability sampling (PPS) method, 1 primary school, 1 junior high school and 1 senior high school in urban areas and 2 primary schools, 2 junior high schools and 2 senior high schools in rural areas were selected from each geographic distribution. Then, one class was randomly selected from each grade in selected schools. Finally, all students aged 6-17 years in selected classes were eligible to participate in this study. A total of 27 schools, 81 classes, and 4898 students were recruited between June 2011 and July 2011. All students voluntarily joined this study and written informed consent was obtained from the parents/guardians of the students. The study was approved by the Ethical Committee of the Shandong Center for Disease Control and Prevention.

\section{Anthropometric measurements}

Anthropometric measurements including height and weight were conducted following the standardized procedures. Weight was measured with the subjects in light clothing (underwear or t-shirt) to the nearest $0.1 \mathrm{~kg}$ on a portable digital beam scale. Height was measured with the subjects barefooted and his/her back facing toward the wall to the nearest $0.1 \mathrm{~cm}$ using a tape measure and a square.

BMI was then calculated as weight in kilograms divided by the square of height in meters. The Working Group on Obesity in China (WGOC) definitions for childhood overweight and obesity $(>=85$ th and 95th percentile of BMI) were applied [11]. Subjects were classified by BMI as non-overweight (below the cut-off point for overweight), overweight (above the cut-off point for overweight) and obesity (above the cut-off point for obesity).

\section{BP measurements}

Systolic blood pressure (SBP) and diastolic blood pressure (DBP) were measured after the subjects had rested for at least 5 minutes in a sitting position. BP was measured three times on the right arm using an electronic sphygmomanometer (HEM-7071, Omron Corporation, Japan) and appropriately sized cuff. Three readings were taken at one-minute intervals during which time the subjects were left alone. The arithmetic mean of three $\mathrm{BP}$ readings was calculated and used for analysis.

The age- and gender-specific BP cut-off points in Chinese children and adolescents were used to define relatively high $\mathrm{BP}$ status [12]. In this definition, high $\mathrm{BP}$ status was defined as SBP and/or DBP above the 95th percentile for age and gender.

\section{Statistical analyses}

Descriptive statistics for height, weight, BMI, SBP, and DBP were calculated by gender and age group, and presented as the mean and standard deviation (SD). The prevalence of high BP, overweight, and obesity was presented as frequencies. To estimate the relationship between BP and BMI, SBP and DBP for age and BMI groups were also calculated. Weighted prevalence was estimated taking differential probabilities of selection and the complex sampling design into account. Comparisons of differences by gender and age groups were conducted using Pearson's chi-square tests. Logistic regression was performed to calculate the odds ratios (ORs) and their 95\% confidence intervals (CIs) of different BMI categories for high BP after adjusting for age and gender. All statistical tests were two-sided and considered statistically significant at a $p$ value $<0.05$. Statistical analyses were performed using SPSS statistical package version 16 for windows (SPSS Inc., Chicago, IL, USA).

\section{Data quality control}

A set of strategies was implemented to control data quality. All medical measurements were performed using the same type of apparatus by a trained physician or pediatrician. Health data collection sheets were checked every day to identify questionable information in time. Data was double entered into Epi-data 3.1 software, cleaning and archiving was conducted using established protocols.

\section{Results}

Of the 4898 children and adolescents enrolled into the study, completed usable data was available for 4898 
(Response rate $100.0 \%$ ) subjects, comprising 2534 boys and 2364 girls, with a mean age of $11.7 \pm 3.3$ years. $35.3 \%$ of the subjects lived in urban areas.

Table 1 showed the descriptive characteristics of the subjects, as stratified by gender and age. Weight, height, BMI, SBP, and DBP increased with increasing age in both genders. Mean SBP increased by $17.5 \mathrm{mmHg}$ and DBP increased by $4.4 \mathrm{mmHg}$ in boys; SBP increased by $10.7 \mathrm{mmHg}$ and DBP increased by $3.0 \mathrm{mmHg}$ in girls from 6-8 years to 15-17 years age group, respectively. Mean BMI increased by $4.4 \mathrm{~kg} / \mathrm{m}^{2}$ and $4.6 \mathrm{~kg} / \mathrm{m}^{2}$ for boys and girls, respectively. Mean BMI of boys was higher than that of girls $(\mathrm{t}=3.22, p<0.05)$. As shown in Figures 1 and 2, both SBP and DBP increased in parallel with increasing BMI among all stratified age groups.

The prevalence of overweight and obesity among children and adolescents aged 6-17 years in Shandong were presented in Table 2. In 2011, the crude prevalence of overweight, obesity and overweight plus obesity were $10.9 \%, 8.7 \%$ and $19.6 \%$, while the weighted prevalence were $11.0 \%, 7.7 \%$ and $18.7 \%$, respectively. Boys were significantly more likely to be overweight or obese than girls $(12.0 \%$ vs $9.8 \%, P<0.05$ for overweight; $10.9 \%$ vs $6.2 \%, P<0.001$ for obesity). There were some differences in age trend between prevalence of overweight and obesity. Across age groups, prevalence of overweight ranged from $10.3 \%$ to $11.9 \%(P>0.05)$; whereas prevalence of obesity was elevated with increasing age at first, reached to the highest percentage $(12.0 \%)$ among children aged 9-11 years, then decreased to $5.3 \%$ among those aged 15-17 years $(P<0.001)$. A similar trend was observed when prevalence of overweight plus obesity was broken down by age. There was no significant difference in prevalence of overweight and obesity between urban and rural children.

Table 3 showed prevalence of high BP among different BMI categories. The prevalence of high BP in nonoverweight, overweight and obesity groups were $11.4 \%$, $24.9 \%$ and $38.7 \%$, respectively. Overweight and obese children had higher BP and showed a significantly higher prevalence of high BP than non-overweight group $(P<0.001)$. The adjusted ORs for high BP increased with increasing obese status classified by BMI categories.

\section{Discussion}

In this cross-sectional study, we examined the prevalence of overweight and obesity and their relationship with $\mathrm{BP}$ in a randomly selected representative sample among children and adolescents aged 6-17 years in Shandong. Our study showed that a considerable proportion (19.6\%) of children and adolescents was overweight or obese. Compared with non-overweight children, those who were overweight or obese showed a significantly higher prevalence of high BP.

At present, childhood obesity has become a serious public health problem in the world. In the United States, up to $18 \%$ of children and adolescents are obese [13]. Prevalence of overweight plus obesity has been reported to be $20-30 \%$ in some European countries, including Spain, Italy, and Greece [14-16]. Similar findings are being seen in developing countries as well. $15.7 \%$ of adolescents in Brazil are reported to have excess weight [17]. In China, the prevalence of obesity increased from $0.13 \%$ and $0.12 \%$ in 1985 , to $1.4 \%$ and $0.9 \%$ in 1995 , and

Table 1 Descriptive characteristics of participants

\begin{tabular}{|c|c|c|c|c|c|c|}
\hline Age group(years) & Number & Height(cm) & Weight(kg) & $\operatorname{BMI}\left(\mathrm{kg} / \mathrm{m}^{2}\right)$ & $\mathrm{SBP}(\mathrm{mmHg})$ & $\mathrm{DBP}(\mathrm{mmHg})$ \\
\hline \multicolumn{7}{|l|}{ Boys } \\
\hline $6-8$ & 593 & $126.9 \pm 7.4$ & $27.2 \pm 7.2$ & $16.8 \pm 3.7$ & $99.8 \pm 10.1$ & $65.0 \pm 8.8$ \\
\hline $9-11$ & 599 & $140.5 \pm 8.3$ & $37.0 \pm 10.8$ & $18.5 \pm 4.0$ & $104.6 \pm 10.9$ & $67.6 \pm 9.4$ \\
\hline $12-14$ & 755 & $160.3 \pm 9.8$ & $51.3 \pm 13.4$ & $19.8 \pm 3.9$ & $113.3 \pm 11.7$ & $68.0 \pm 8.7$ \\
\hline $15-17$ & 587 & $171.6 \pm 7.2$ & $62.6 \pm 13.1$ & $21.2 \pm 4.0$ & $117.3 \pm 11.6$ & $69.4 \pm 9.4$ \\
\hline \multicolumn{7}{|l|}{ Girls } \\
\hline $6-8$ & 481 & $125.9 \pm 8.0$ & $26.0 \pm 6.3$ & $16.2 \pm 2.4$ & $99.2 \pm 10.7$ & $66.7 \pm 9.0$ \\
\hline $9-11$ & 532 & $140.7 \pm 8.4$ & $34.6 \pm 9.9$ & $17.3 \pm 3.8$ & $103.0 \pm 10.2$ & $68.5 \pm 8.8$ \\
\hline $12-14$ & 703 & $156.8 \pm 6.9$ & $48.3 \pm 11.5$ & $19.6 \pm 4.0$ & $109.6 \pm 10.9$ & $69.6 \pm 8.3$ \\
\hline $15-17$ & 648 & $160.9 \pm 6.6$ & $53.6 \pm 8.6$ & $20.8 \pm 5.0$ & $109.9 \pm 10.0$ & $69.7 \pm 8.7$ \\
\hline \multicolumn{7}{|l|}{ All } \\
\hline $6-8$ & 1074 & $126.5 \pm 7.7$ & $26.7 \pm 6.9$ & $16.5 \pm 3.2$ & $99.6 \pm 10.4$ & $65.7 \pm 8.9$ \\
\hline $9-11$ & 1131 & $140.6 \pm 8.4$ & $35.9 \pm 10.5$ & $17.9 \pm 3.9$ & $103.9 \pm 10.6$ & $68.0 \pm 9.1$ \\
\hline $12-14$ & 1458 & $158.6 \pm 8.7$ & $49.9 \pm 12.6$ & $19.7 \pm 4.0$ & $111.5 \pm 11.5$ & $68.8 \pm 8.5$ \\
\hline $15-17$ & 1235 & $166.0 \pm 8.8$ & $57.9 \pm 11.9$ & $21.0 \pm 4.5$ & $112.9 \pm 10.0$ & $69.7 \pm 8.7$ \\
\hline
\end{tabular}

Note. Mean \pm Standard Deviation; BMI, Body mass index; SBP, Systolic blood pressure; DBP, Diastolic blood pressure. 


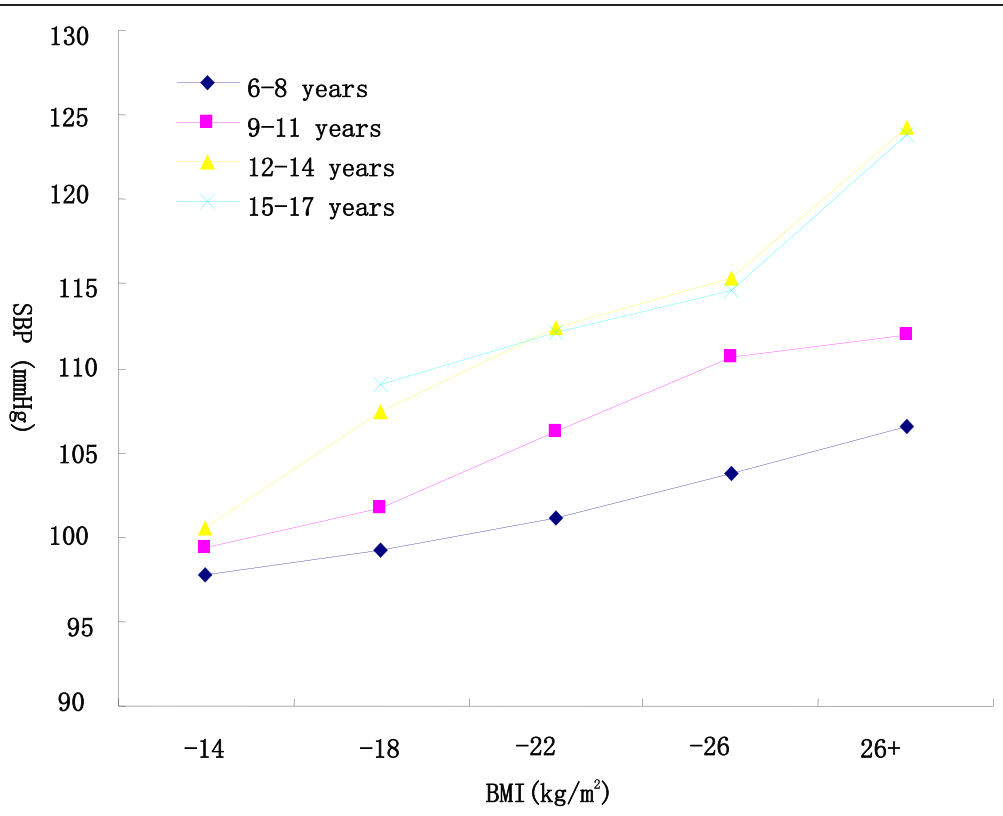

Figure 1 Mean systolic blood pressure (SBP) in different body mass index (BMI) categories, age-specific.

to $5.1 \%$ and $2.7 \%$ in 2005 , for boys and girls among children and adolescents aged 7-18 years [18].

The prevalence of overweight plus obesity obtained in our study exceeded the results of the China Health and Nutrition Survey (CHNSs) in 2009(18.0\%) [19], but was lower than that of studies in large cities in recent years, such as Shanghai(24.8\%) and Tianjin(28.2\%) [20,21]. It may be possible that only 1108 children aged $7-18$ years from 9 provinces participated in the CHNSs, which mean a small sample size. Compared to the results from Shanghai and Tianjin, the differences may be explained by different economic status. The prevalence of overweight plus obesity was the highest (one in five) among children aged 6-11 years. The finding was in line with other studies [22]. The special patterns of growth and maturation during adolescence may help explain the phenomena. A rapid increase in percentage of body fat and peak bone accretion may be observed among children aged 6-11 years. In our study, the prevalence of overweight and obesity was higher in boys than in girls. Gender-specific disparities in childhood obesity had been documented worldwide [23,24]. Previous studies showed that differences in sedentary behaviors, genetics, and socio-cultural and economic factors may account for some of these disparities [25]. In China, traditional ideas of preferring boys over girls leading to disparities in food availability may be one of the unique reasons. Studies done in developed countries showed that rural children

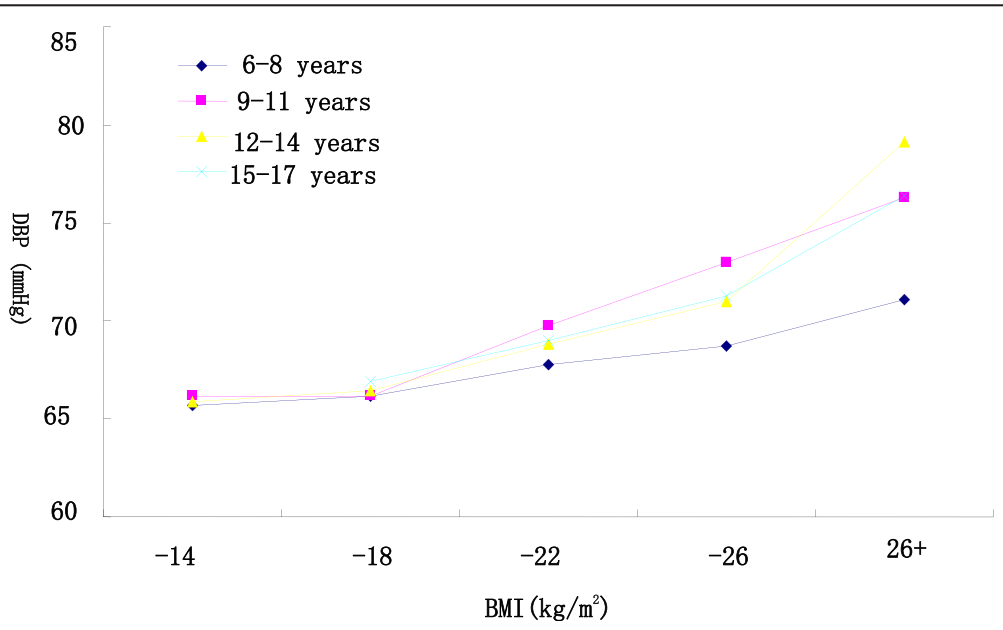

Figure 2 Mean diastolic blood pressure (DBP) in different body mass index (BMI) categories, age-specific. 
Table 2 Prevalence of overweight and obesity among children and adolescents aged 6-17 years in Shandong

\begin{tabular}{|c|c|c|c|c|c|c|c|c|c|}
\hline \multirow[t]{2}{*}{ Variable } & \multicolumn{3}{|c|}{ Boys (\%) } & \multicolumn{3}{|c|}{ Girls (\%) } & \multicolumn{3}{|c|}{ All (\%) } \\
\hline & Overweight & Obesity & Both & Overweight & Obesity & Botha & Overweight & Obesity & Both \\
\hline \multicolumn{10}{|c|}{ Age group (years) } \\
\hline $6 \sim 8$ & 12.1 & 11.1 & 23.2 & 9.6 & 11.2 & 20.8 & 11.0 & 11.2 & 22.2 \\
\hline $9 \sim 11$ & 11.5 & 16.2 & 27.7 & 8.8 & 7.3 & 16.1 & 10.3 & 12.0 & 22.3 \\
\hline $12 \sim 14$ & 13.6 & 8.7 & 22.3 & 10.0 & 5.3 & 15.3 & 11.9 & 7.1 & 19.0 \\
\hline $15 \sim 17$ & 10.2 & 8.2 & 18.4 & 10.5 & 2.6 & 13.1 & 10.4 & 5.3 & 15.7 \\
\hline \multicolumn{10}{|c|}{ Residence area } \\
\hline Urban & 12.9 & 12.0 & 24.9 & 11.9 & 6.1 & 18.0 & 12.4 & 9.1 & 21.5 \\
\hline Rural & 11.5 & 10.3 & 21.8 & 8.6 & 6.3 & 14.9 & 10.1 & 8.4 & 18.5 \\
\hline \multirow[t]{2}{*}{ Total } & 12.0 & 10.9 & 22.9 & 9.8 & 6.2 & 16.0 & 10.9 & 8.7 & 19.6 \\
\hline & $12.1^{\mathrm{a}}$ & $9.4^{\mathrm{a}}$ & $21.5^{\mathrm{a}}$ & $9.7^{a}$ & $5.8^{a}$ & $15.5^{\mathrm{a}}$ & 11.0 & 7.7 & 18.7 \\
\hline
\end{tabular}

Note. Both, Overweight + Obesity.

a'Weighted prevalence was calculated taking into account differential probabilities of selection and the complex sampling design.

had a higher risk of overweight and obesity than urban children, whereas developing countries showed a reverse association [26,27]. Our study indicated that children from rural areas were similar to their peers from urban areas in obesity epidemic. One of the main reasons maybe the decrease in urban-rural disparities. In addition, urban schools and parents may pay more attention on children obesity than rural ones.

Previous studies led to conflicting results as to whether there was an association between obesity and high BP in children. A study conducted in Changsha indicated that the risk ratio (RR) of hypertension were significantly higher in overweight (RR: $2.8,95 \%$ confidence interval (CI): 2.6-3.2) and obese (RR: 8.7, 95\% CI: 8.1-9.5) adolescents adjusted for age, sex, and height [28]. Another study of 8568 students aged 7-18 years conducted in Shandong in 2005 reported that prevalence of relatively high BP increased with BMI percentiles and this trend was especially obvious in the upper percentiles of BMI [10]. However, a study conducted in Anhui showed no relationship between measures of adiposity and DBP among rural children aged 12-18 years [29]. The variations in adiposity measures, dietary intake, socioeconomic status, and physical activity may lead to these different results [28].

The study had several strengths. First, the database came from a large representative sample of children and adolescents in Shandong. We were able to analyze data separately in gender- and age-specific subgroups. Second, a set of strategies was implemented to ensure the high quality of the data, such as objectively measured BMI. However, several limitations should be considered. First, since the current study was crosssectional, it was impossible to establish the causality relationships. Second, overweight, obesity and high BP were defined by Chinese criteria in the study. Therefore,

Table 3 Prevalence of high BP among different BMI Categories

\begin{tabular}{|c|c|c|c|c|c|}
\hline Gender & BMI Categories & $\mathrm{SBP}(\mathrm{mm} \mathrm{Hg})$ & $\mathrm{DBP}(\mathrm{mm} \mathrm{Hg})$ & High BP(\%) & OR(95\% Cl) \\
\hline \multirow[t]{4}{*}{ Boys } & Non-overweight & $107.7 \pm 12.1$ & $66.3 \pm 8.3$ & 10.7 & 1.0 \\
\hline & Overweight & $112.3 \pm 13.4$ & $70.0 \pm 9.7$ & 25.0 & $2.0(1.4,2.8)$ \\
\hline & Obesity & $114.9 \pm 16.2$ & $73.8 \pm 11.2$ & 38.6 & $2.7(1.8,4.1)$ \\
\hline & Total & $109.0 \pm 13.0$ & $67.5 \pm 9.2$ & 15.4 & \\
\hline \multirow[t]{4}{*}{ Girls } & Non-overweight & $105.1 \pm 11.0$ & $68.0 \pm 8.4$ & 12.1 & 1.0 \\
\hline & Overweight & $108.7 \pm 11.6$ & $71.0 \pm 8.8$ & 24.7 & $2.4(1.7,3.3)$ \\
\hline & Obesity & $110.7 \pm 12.9$ & $74.4 \pm 10.2$ & 38.8 & $4.2(2.9,6.1)$ \\
\hline & Total & $105.8 \pm 11.3$ & $68.8 \pm 8.7$ & 15.0 & \\
\hline \multirow[t]{4}{*}{ Total } & Non-overweight & $106.4 \pm 11.6$ & $67.2 \pm 8.4$ & 11.4 & 1.0 \\
\hline & Overweight & $110.7 \pm 12.8$ & $70.4 \pm 9.4$ & 24.9 & $2.2(1.7,2.8)$ \\
\hline & Obesity & $113.4 \pm 15.2$ & $74.0 \pm 10.9$ & 38.7 & $3.6(2.6,4.9)$ \\
\hline & Total & $107.5 \pm 12.3$ & $68.1 \pm 9.0$ & 15.2 & \\
\hline
\end{tabular}


results of the study might not be comparable with other findings.

\section{Conclusions}

In conclusion, this study demonstrated that the prevalence of childhood obesity was high in Shandong, one of the populous provinces in China. BP and prevalence of high BP were significantly higher in overweight/obese children than in non-overweight ones, suggesting that overweight/obesity was a strong risk factor. Obesity has become a health threat to children and adolescents in Shandong, and as the urbanization increases, childhood obesity might show further increase. Thus, urgent effort should be made to combat the growing childhood obesity epidemic.

\section{Competing interests}

The authors declare that they have no competing interests.

\section{Authors' contributions}

AQX developed the study design, carried out the study, analyzed the data and wrote the manuscript. JD and XLG were involved in conducting the statistical analyses, interpreting the results and drafting the manuscript. ZLL and JYZ organized the cross-sectional study and assisted with preparing the manuscript. XNC, HCW and LXY contributed to analyzed the data. All authors read and approved the final manuscript.

\section{Acknowledgements}

The survey was supported by funds from Chinese Center for Disease Control and Prevention (China CDC), National Center for Non-communicable and Chronic Disease Control and Prevention (NCNCD, China CDC), the Technical Development Plan in Shandong (implemented by Shandong CDC, Grant number: 2012GSF11828). We thank all the investigators from national, Shandong provincial and county level CDC and all participants of the survey.

\section{Author details}

${ }^{1}$ Department of Non-communicable Disease Control and Prevention, Shandong Center for Disease Control and Prevention, 16992 Jingshi Road, Jinan 250014, China. ${ }^{2}$ National Center for Chronic and Non-communicable Disease Control and Prevention, Chinese Center for Disease Control and Prevention, Beijing 100050, China. ${ }^{3}$ Department of Tobacco Control, Chinese Center for Disease Control and Prevention, Beijing 102206, China.

Received: 24 June 2014 Accepted: 9 October 2014 Published: 17 October 2014

\section{References}

1. Wang $Y$, Lobstein T: Worldwide trends in childhood overweight and obesity. Int J Pediatr Obes 2006, 1:11-25.

2. De Onis $M$, Lobstein $T$ : Defining obesity risk status in the general childhood population: which cut-offs should we use? Int J Pediatr Obes 2010, 5:458-460.

3. Raj M: Obesity and cardiovascular risk in children and adolescents. Indian $J$ Endocrinol Metab 2012, 16:13-19.

4. Wang L, Kong L, Wu F, Bai Y, Burton R: Preventing chronic diseases in China. Lancet 2005, 366:1821-1824.

5. Seo DC, Niu J: Trends in underweight and overweight/obesity prevalence in Chinese youth, 2004-2009. Int J Behav Med 2014, 21:682-690.

6. Rosenbaum M, Leibel RL, Hirsch J: Obesity. N Engl J Med 1997, 337:396-407.

7. Ma J, Wang Z, Dong B, Song Y, Hu P, Zhang B: Quantifying the relationships of blood pressure with weight, height and body mass index in Chinese children and adolescents. J Paediatr Child Health 2012, 48:413-418.

8. Dong B, Ma J, Wang HJ, Wang ZQ: The association of overweight and obesity with blood pressure among Chinese children and adolescents. Biomed Environ Sci 2013, 26:437-444.
9. Zhang YX, Wang SR: Monitoring of blood pressure in overweight and obese children in Shandong, China. Ann Hum Biol 2011, 38:603-607.

10. Zhang YX, Wang SR: The relationship of body mass index distribution to relatively high blood pressure among children and adolescents in Shandong, China. Ann Hum Biol 2011, 38:630-634.

11. WGOC (Working Group on Obesity in China): Body mass index reference norm for screening overweight and obesity in Chinese children and adolescents. Chin J Epidemiol 2004, 2004(25):97-102.

12. Jie MI, Tian-you W, Ling-hui M, Guang-jin Z, Shao-mei H, Yan Z, Gong-shu L, Yan-ping W, Feng $X$, Jing-pu S, Wei-li Y, Pi-ming Z: Development of blood pressure reference standards for Chinese children and adolescents. Chin $J$ Evid Based Pediatr 2010, 5:4-14.

13. Ogden $C L$, Carroll MD, Kit BK, Flegal KM: Prevalence of obesity in the United States, 2009-2010. NCHS Data Brief 2012, 82:1-8.

14. Lazzeri G, Rossi S, Pammolli A, Pilato V, Pozzi T, Giacchi MV: Underweight and overweight among children and adolescents in Tuscany (Italy). Prevalence and short-term trends. J Prev Med Hyg 2008, 49:13-21.

15. Valdés Pizarro J, Royo-Bordonada MA: Prevalence of childhood obesity in Spain: National Health Survey 2006-2007. Nutr Hosp 2012, 27:154-160.

16. Kollias A, Skliros E, Stergiou GS, Leotsakos N, Saridi M, Garifallos D: Obesity and associated cardiovascular risk factors among schoolchildren in Greece: a cross-sectional study and review of the literature. J Pediatr Endocrinol Metab 2011, 24:929-938.

17. Ferreira Marques CD, Ribeiro SilvaR de C, Machado ME, Portelade Santana ML, Castrode Andrade Cairo R, Pinto Ede J, Oliveira Reis Maciel L, Rodrigues Silva $L$ : The prevalence of overweight and obesity in adolescents in Bahia, Brazil. Nutr Hosp 2013, 28:491-496.

18. Ji CY, Working Group on Obesity in China (WGOC): Report on childhood obesity in China (4) prevalence and trends of overweight and obesity in Chinese urban school-age children and adolescents, 1985-2000. Biomed Environ Sci 2009, 20:1-10.

19. Liu XB, Wang QJ, Yuan Y, Li J: Trends in the prevalence of overweight and abdominal obesity among Chinese children aged 7-18 years from 1993 to 2009. CJCHC 2012, 20:117-119. 123.

20. Andegiorgish AK, Wang J, Zhang X, Liu X, Zhu H: Prevalence of overweight, obesity, and associated risk factors among school children and adolescents in Tianjin, China. Eur J Pediatr 2012, 171:697-703.

21. Chen CM: Overview of obesity in mainland China. Obes Rev 2008, 9:14-21.

22. Shan $X Y, X i B$, Cheng H, Hou DQ, Wang Y, Mi J: Prevalence and behavioral risk factors of overweight and obesity among children aged 2-18 in Beijing, China. Int J Pediatr Obes 2010, 5:383-389.

23. Kanter $\mathrm{R}$, Caballero B: Global gender disparities in obesity: a review. Adv Nutr 2012, 3:491-498.

24. Wang Y, Beydoun MA: The obesity epidemic in the United States-gender, age, socioeconomic, racial/ethnic, and geographic characteristics: a systematic review and meta-regression analysis. Epidemiol Rev 2007, 29:6-28.

25. McAllister EJ, Dhurandhar NV, Keith SW, Aronne LJ, Barger J, Baskin M, Benca RM, Biggio J, Boggiano MM, Eisenmann JC, Elobeid M, Fontaine KR, Gluckman P, Hanlon EC, Katzmarzyk P, Pietrobelli A, Redden DT, Ruden DM, Wang C, Waterland RA, Wright SM, Allison DB: Ten putative contributors to the obesity epidemic. Crit Rev Food Sci Nutr 2009, 49:868-913.

26. Davis AM, Bennett KJ, Befort C, Nollen N: Obesity and related health behaviors among urban and rural children in the United States: data from the National Health and Nutrition Examination Survey 2003-2004 and 2005-2006. J Pediatr Psychol 2011, 36:669-676.

27. Mohan B, Kumar N, Aslam N, Rangbulla A, Kumbkarni S, Sood NK, Wander GS: Prevalence of sustained hypertension and obesity in urban and rural school going children in Ludhiana. Indian Heart J 2004, 56:310-314.

28. Cao ZQ, Zhu L, Zhang T, Wu L, Wang Y: Blood pressure and obesity among adolescents: a school-based population study in China. Am J Hyperten 2012, 25:576-582.

29. Wang H, Necheles J, Carnethon M, Wang B, Li Z, Wang L, Liu X, Yang J, Tang G, Xing $H, X u X$, Wang $X$ : Adiposity measures and blood pressure in Chinese children and adolescents. Arch Dis Child 2008, 93:738-744.

\section{doi:10.1186/1471-2458-14-1080}

Cite this article as: Dong et al:: Prevalence of overweight and obesity and their associations with blood pressure among children and adolescents in Shandong, China. BMC Public Health 2014 14:1080. 